\title{
Impact of the revised hemodynamic definition on the diagnosis of precapillary pulmonary hypertension: a retrospective single-center study in China
}

\author{
Qi Jin ${ }^{1,2 \#}$, Yi Zhang ${ }^{1 \#}$, Zhihui Zhao ${ }^{1}$, Qing Zhao ${ }^{1}$, Xue Yu ${ }^{1,3}$, Lu Yan $^{1}$, Xin $^{1}{ }^{1}$, Anqi Duan ${ }^{1}$, Chenhong An ${ }^{1}$, \\ Xiuping $\mathrm{Ma}^{1}$, Changming Xiong ${ }^{1}$, Qin Luo ${ }^{1}$, Zhihong Liu ${ }^{1} \wedge$ \\ ${ }^{1}$ Center for Pulmonary Vascular Diseases, Fuwai Hospital, National Center for Cardiovascular Diseases, Chinese Academy of Medical Sciences \\ and Peking Union Medical College, Beijing, China; ${ }^{2}$ Department of Cardiology, Zhongshan Hospital, Fudan University, Shanghai Institute of \\ Cardiovascular Diseases, Shanghai, China; ${ }^{3}$ Department of Cardiology, Qingdao Municipal Hospital, Qingdao, China \\ Contributions: (I) Conception and design: Z Zhao, Q Zhao, C Xiong; (II) Administrative support: Q Luo, Z Liu; (III) Provision of study materials \\ or patients: Q Jin, Y Zhang, X Yu, L Yan; (IV) Collection and assembly of data: Q Jin, Y Zhang, X Li, A Duan, C An, X Ma; (V) Data analysis and \\ interpretation: Q Jin, Y Zhang; (VI) Manuscript writing: All authors; (VII) Final approval of manuscript: All authors. \\ \#These authors contributed equally to this work. \\ Correspondence to: Qin Luo, PhD; Zhihong Liu, PhD. Center for Pulmonary Vascular Diseases, Fuwai Hospital, National Center for Cardiovascular \\ Diseases, Chinese Academy of Medical Sciences and Peking Union Medical College, No. 167 Beilishi Rd, Xicheng District, Beijing 100037, China. \\ Email: luoqin2009@163.com; zhihongliufuwai@163.com.
}

Background: In the $6^{\text {th }}$ World Symposium on Pulmonary Hypertension (PH), the hemodynamic definition of $\mathrm{PH}$ was reduced from a mean pulmonary artery pressure (mPAP) $\geq 25$ to $>20 \mathrm{mmHg}$. This study aimed to evaluate the impact of the revised hemodynamic definition on the diagnosis of precapillary PH.

Methods: We retrospectively enrolled patients who underwent right heart catheterization from January 2012 to December 2018. All included patients were reassessed according to the revised hemodynamic definition.

Results: A total of 1,251 patients were included for analysis, of whom 1,044 patients had precapillary $\mathrm{PH}$ and 182 patients had mPAP <25 mmHg. After applying the revised definition, 33 (18.1\%) of 182 patients with $\mathrm{mPAP}<25 \mathrm{mmHg}$ were reclassified as having PH. However, only 7 of these 33 patients had a pulmonary vascular resistance $\geq 3$ wood units and could be considered to have precapillary $\mathrm{PH}$, accounting for $0.7 \%$ of the existing precapillary $\mathrm{PH}$ population. More importantly, 12 patients with $\mathrm{mPAP} \geq 25 \mathrm{mmHg}$ were delisted from precapillary $\mathrm{PH}$ for pulmonary vascular resistance $<3$ wood units ( 5 patients from Group III, 4 patients from Group IV, 3 patients from Group V). Overall, there was a net $0.5 \%$ decrease $[(12-7) / 1044 \times 100 \%]$ in the population with precapillary $\mathrm{PH}$.

Conclusions: The revised hemodynamic definition had a minor impact on the diagnosis of precapillary PH. It should be noted that the revised definition would influence not only patients with mPAP $=21-24$ $\mathrm{mmHg}$, but also patients with $\mathrm{mPAP} \geq 25 \mathrm{mmHg}$.

Keywords: Pulmonary hypertension; precapillary pulmonary hypertension; hemodynamics; diagnosis

Submitted Jul 18, 2021. Accepted for publication Aug 23, 2021.

doi: $10.21037 / \mathrm{cdt}-21-373$

View this article at: https://dx.doi.org/10.21037/cdt-21-373

^ ORCID: 0000-0001-8639-6306. 


\section{Introduction}

In 2015, the European Society of Cardiology (ESC)/ European Respiratory Society (ERS) introduced the most widely recognized and used guidelines for the diagnosis and treatment of pulmonary hypertension (PH). The 2015 ESC/ERS guidelines define $\mathrm{PH}$ as a mean pulmonary artery pressure $(\mathrm{mPAP}) \geq 25 \mathrm{mmHg}$ measured by right heart catheterization (RHC) at rest (1). Compared with its 2009 version (2), the 2015 ESC/ERS guidelines incorporate pulmonary vascular resistance $(\mathrm{PVR})>3$ wood units (WU) into the hemodynamic definition of pulmonary arterial hypertension (PAH) (Group I).

Based on robust evidence, a task force proposed lowering the upper threshold of mPAP to $>20 \mathrm{mmHg}$ and incorporating PVR $\geq 3$ into the hemodynamic definition of all forms of precapillary PH (Groups I, III, IV, V) during the $6^{\text {th }}$ World Symposium on Pulmonary Hypertension (WSPH) (3). Given that this change may affect the next version of the guidelines for $\mathrm{PH}$, the impact of the revised definition on current clinical practice deserves a thorough evaluation. Although several studies have focused on this topic, there are still many unresolved questions.

Some of these studies only enrolled patients with systemic sclerosis (SSc)-associated PAH (4,5). One study attempted to enroll all forms of precapillary $\mathrm{PH}$, but its study cohort was quite small $(n=58)(6)$. In a single-center study with 1,300 patients, Tanyeri et al. (7) reported that the revised definition would only increase the population of $\mathrm{PH}$, precapillary $\mathrm{PH}$ and combined pre- and postcapillary $\mathrm{PH}$ by $9.8 \%, 0.8 \%$ and $0.3 \%$, respectively. Unfortunately, Tanyeri et al. (7) did not perform a subgroup analysis within precapillary $\mathrm{PH}$. Moreover, previous studies mainly discussed the impact of the revised definition on borderline $\mathrm{PH}$ ( $\mathrm{mPAP}=21-24 \mathrm{mmHg}$ ). Incorporating PVR into the hemodynamic definition of all forms of precapillary $\mathrm{PH}$ could also influence patients with established precapillary PH (mPAP $\geq 25 \mathrm{mmHg}$ ). However, we could not find answers to this question in published papers. In addition, comprehensive studies with large sample sizes or data from different expert $\mathrm{PH}$ centers in different countries are scarce. The aim of the present study was to evaluate the impact of the revised definition on current clinical practice in a tertiary $\mathrm{PH}$ center in China. We present the following article in accordance with the STROBE reporting checklist (available at https://dx.doi.org/10.21037/cdt-21-373).

\section{Methods}

\section{Study cohort}

We retrospectively reviewed the medical records of patients who underwent RHC at Fuwai Hospital, National Center for Cardiovascular Diseases, China, from January 2012 to December 2018. For patients who underwent multiple RHC procedures during the study period, we only used their first RHC records. The establishment of precapillary $\mathrm{PH}$ and its classification were determined by two physicians specialized in $\mathrm{PH}$, who followed the 2009 (before January 2016) or 2015 ESC/ERS guidelines $(1,2)$. Patients were excluded from the current analysis if they (I) had incomplete hemodynamic data [mPAP, pulmonary arterial wedge pressure (PAWP) or cardiac output] and (II) had a PAWP >15 mmHg. However, patients with mPAP $\leq 20 \mathrm{mmHg}$ were exempted from the exclusion criteria, because hemodynamic parameters other than mPAP were not required in the current study. Chronic thromboembolic pulmonary disease (CTEPD) is defined as patients with chronic thromboembolism (CTE) who have symptoms and perfusion defects similar to chronic thromboembolic pulmonary hypertension (CTEPH) but they have normal hemodynamics at rest (8). Unclassifiable $\mathrm{PH}$ in the present study is hemodynamically defined as: patients who had abnormal hemodynamics but did not meet the $2015 \mathrm{ESC} /$ ERS criteria for PAH (i.e., $\mathrm{mPAP} \geq 25 \mathrm{mmHg}$, PAWP $\leq 15 \mathrm{mmHg}$, and $\mathrm{PVR} \leq 3 \mathrm{WU}$ ) or patients who had abnormal hemodynamics but did not meet the $6^{\text {th }}$ WSPH criteria for precapillary $\mathrm{PH}$ (i.e., $\mathrm{mPAP}>20 \mathrm{mmHg}$, PAWP $\leq 15 \mathrm{mmHg}$, and PVR $<3 \mathrm{WU}$ ). The study was conducted in accordance with the Declaration of Helsinki (as revised in 2013). The study was approved by ethics board of Fuwai Hospital (NO.: 2019-1191) and individual consent for this retrospective analysis was waived.

To maximize the sample size of the study cohort, we included patients diagnosed by the 2009 ESC/ERS guidelines. Given that the aim of this study was to evaluate the impact of the revised hemodynamic definition on current clinical practice, we used the 2015 ESC/ERS guidelines to reclassify these patients. At this stage, all included patients were retrospectively re-diagnosed by the 2015 ESC/ERS guidelines. The reclassification process was feasible because there are only subtle differences in clinical classifications and hemodynamic definitions between the 2009 and the 2015 


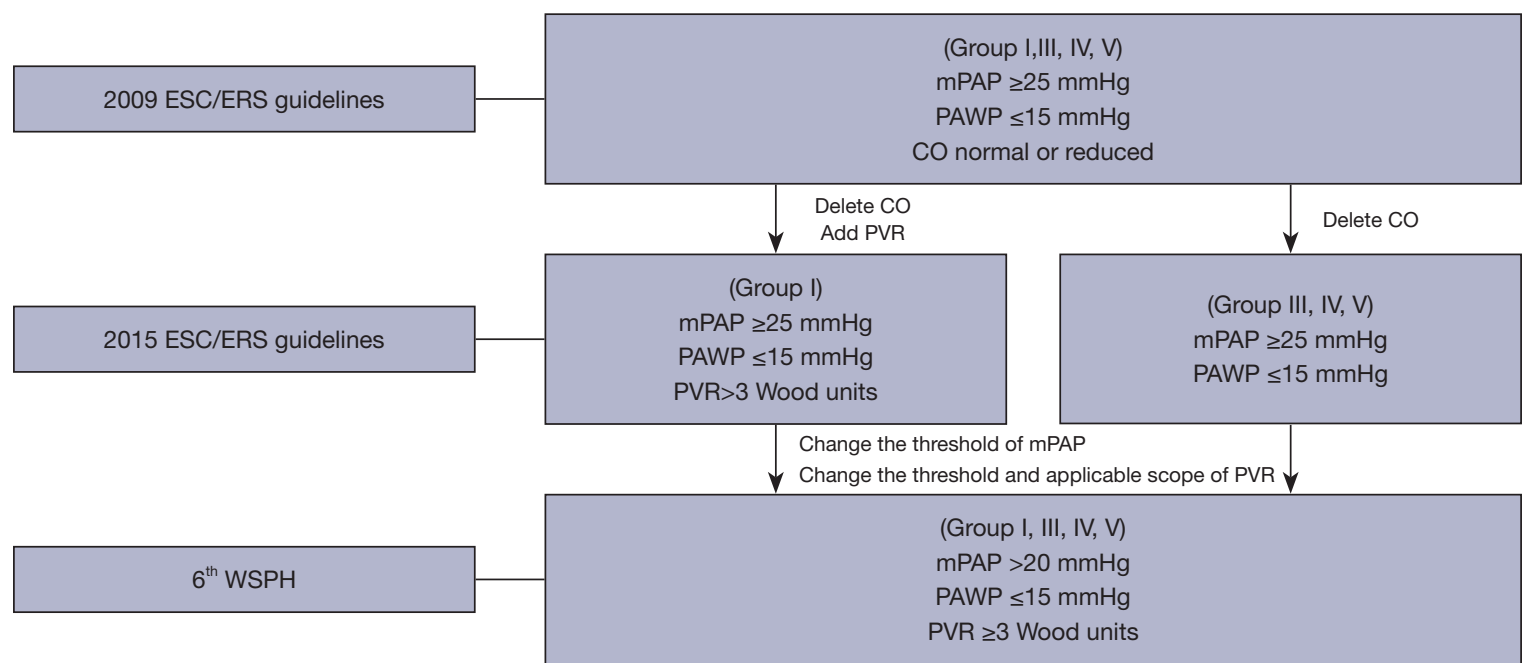

Figure 1 The differences in hemodynamic definitions among the 2009 ESC/ERS guidelines, 2015 ESC/ERS guidelines and $6^{\text {th }}$ WSPH. $^{2}$ CO, cardiac output; ERS, European Respiratory Society; ESC, European Society of Cardiology; mPAP, mean pulmonary arterial pressure; PAWP, pulmonary arterial wedge pressure; PVR, pulmonary vascular resistance; WSPH, World Symposium on Pulmonary Hypertension.

ESC/ERS guidelines (see Figure 1). Finally, we performed a second reclassification process, using the $6^{\text {th }} \mathrm{WSPH}$ criteria to reclassify all included patients.

\section{Data collection}

The following clinical data were collected from the electronic medical record system by two reviewers: (I) basic characteristics, including age, sex, body mass index, etiology of $\mathrm{PH}$, comorbidities, and $\mathrm{PH}$ specific medication at the time of RHC; (II) RHC parameters; (III) echocardiographic parameters; and (IV) cardiopulmonary exercise testing (CPET) parameters. Any discordance was resolved by the supervisors (QL and ZHL).

\section{Protocols for echocardiography, RHC and CPET}

Details of the protocol of RHC and CPET have been described in our previous publications (9-12). With local anesthesia under continuous electrocardiographic monitoring, a 6 French pigtail catheter or 7 French SwanGanz catheter (Edwards Lifesciences World Trade Co. Ltd, Irvine, CA, USA) was advanced into the pulmonary artery through the right femoral vein or right internal jugular vein by placement of a 6 or 7 French vascular sheath. Correct catheter positioning was verified by fluoroscopy. Transducers were positioned at the midaxillary line and zeroed at atmospheric pressure. An incremental symptom-limited CPET was performed on an upright cycle ergometer using the COSMED Quark PET system (COSMED, Rome, Italy), within 3 days prior to RHC. Transthoracic echocardiography was performed by experienced ultrasonologists in the Department of Echocardiography.

\section{Statistical analysis}

Continuous variables are presented as the mean \pm standard deviation. Categorical variables are given as counts. Not a single missing value was replaced. Data analysis was performed using SPSS version 23.0 (IBM SPSS Corp.; Armonk, NY, USA).

\section{Results}

\section{Patients enrollment}

From January 2012 to December 2018, 1,523 patients received RHC at our center. Two hundred and seventytwo patients with incomplete hemodynamic data $(\mathrm{N}=209)$ or PAWP $>15 \mathrm{mmHg}(\mathrm{N}=63)$ were excluded. Among the remaining 1,251 patients, 429 were originally diagnosed by the 2009 ESC/ERS guidelines (Jan 2012 to Dec 2015) and 822 were originally diagnosed by the 2015 ESC/ERS 


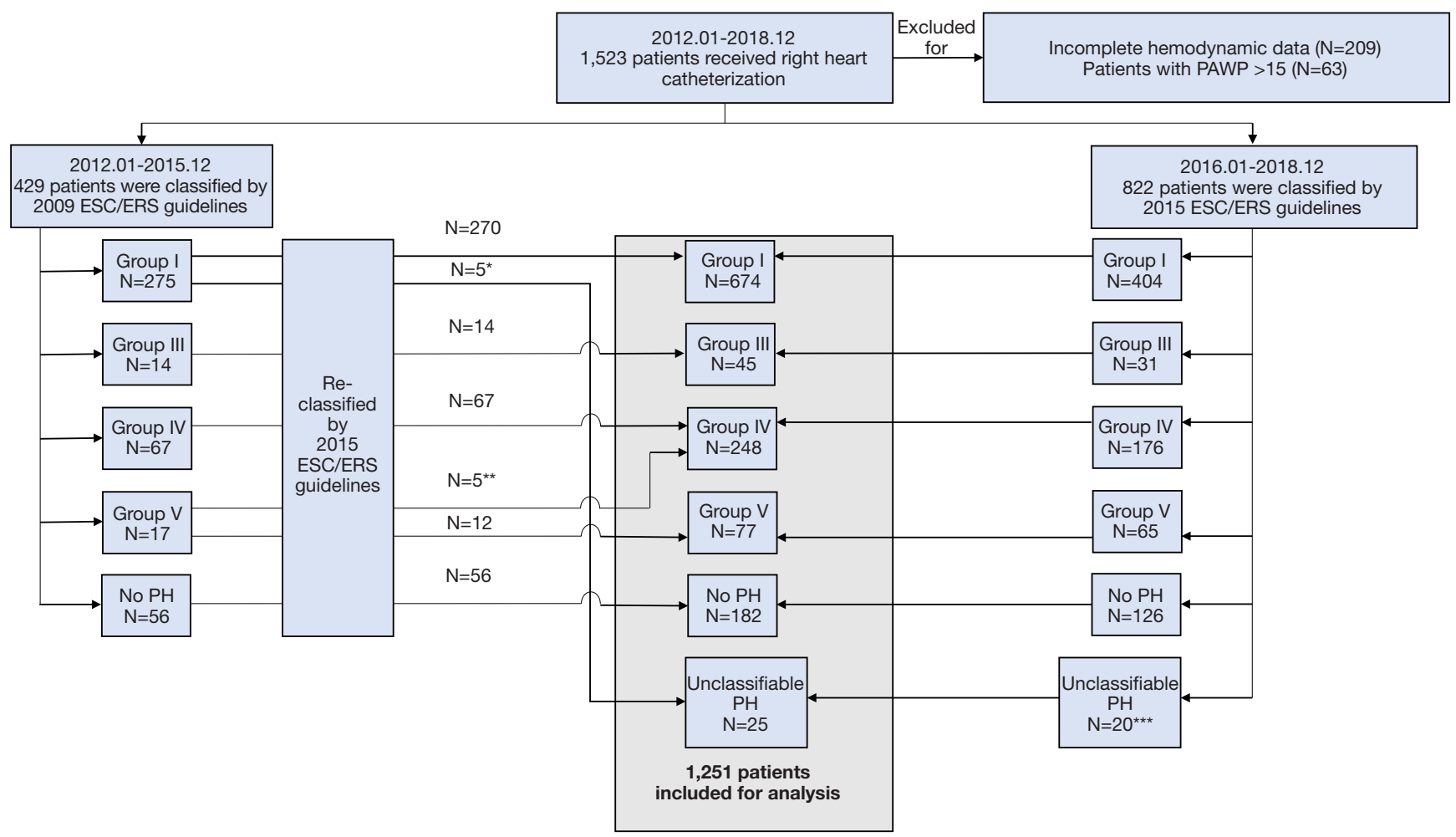

Figure 2 Flowchart of the included and excluded patients in our study. *, One IPAH and 4 CHD-PAH could no longer be subgrouped as Group I for PVR $\leq 3$ wood units under the 2015 ESC/ERS guidelines. **, One PH associated with tumor obstruction and 4 PH associated with vasculitis were reclassified as Group IV. ${ }^{* * *}$, All patients had congenital heart disease associated with pulmonary hypertension, but they could not be subgrouped as Group I for PVR $\leq 3$ wood units under the 2015 ESC/ERS guidelines. CHD-PAH, pulmonary arterial hypertension associated with congenital heart disease; ERS, European Respiratory Society; ESC, European Society of Cardiology; IPAH, idiopathic pulmonary arterial hypertension; PAWP, pulmonary arterial wedge pressure; PH, pulmonary hypertension; PVR, pulmonary vascular resistance.

guidelines (Jan 2016 to Dec 2018).

\section{First reclassification process}

We reclassified 429 patients who were diagnosed by the 2009 ESC/ERS guidelines, using the 2015 ESC/ERS guidelines. One idiopathic PAH and four pulmonary arterial hypertension associated with congenital heart disease could no longer be sugrouped as Group I due to PVR $\leq 3 \mathrm{WU}$; one $\mathrm{PH}$ associated with tumor obstruction and four $\mathrm{PH}$ associated with vasculitis were reclassified as Group IV (PH associated with tumor obstruction or vasculitis was classified as Group V in the 2009 ESC/ERS guidelines, but was classified as Group IV in the 2015 ESC/ERS guidelines). At this stage, all patients $(\mathrm{N}=1,251)$ were diagnosed and included in the analysis according to the 2015 ESC/ERS guidelines (Group I, N=674; Group III, N=45; Group IV,
$\mathrm{N}=248$; Group V, N=77; Unclassifiable $\mathrm{PH}, \mathrm{N}=25$; No $\mathrm{PH}, \mathrm{N}=182$ ). A flow-chart displaying the enrollment and first reclassification process is illustrated in Figure 2, and the clinical characteristics of the study cohort, stratified by mPAP and PVR, are presented in Table 1.

\section{Second re-classification process}

We reclassified all included patients $(\mathrm{N}=1,251)$ using the $6^{\text {th }} \mathrm{WSPH}$ criteria. Among patients with mPAP $\geq 25 \mathrm{mmHg}(\mathrm{N}=1,069), 12(1.1 \%)$ patients were removed from precapillary $\mathrm{PH}$ for PVR $<3 \mathrm{WU}$ (5 patients from Group III; 4 patients from Group IV; 3 patients from Group V). Among patients with mPAP $<25 \mathrm{mmHg}(\mathrm{N}=182)$, $33(18.1 \%)$ were newly identified as having PH. Among patients with newly identified $\mathrm{PH}, 7$ patients with PVR $\geq 3 \mathrm{WU}$ could be considered as having precapillary $\mathrm{PH}$ 
Table 1 Clinical characteristics of the study cohort

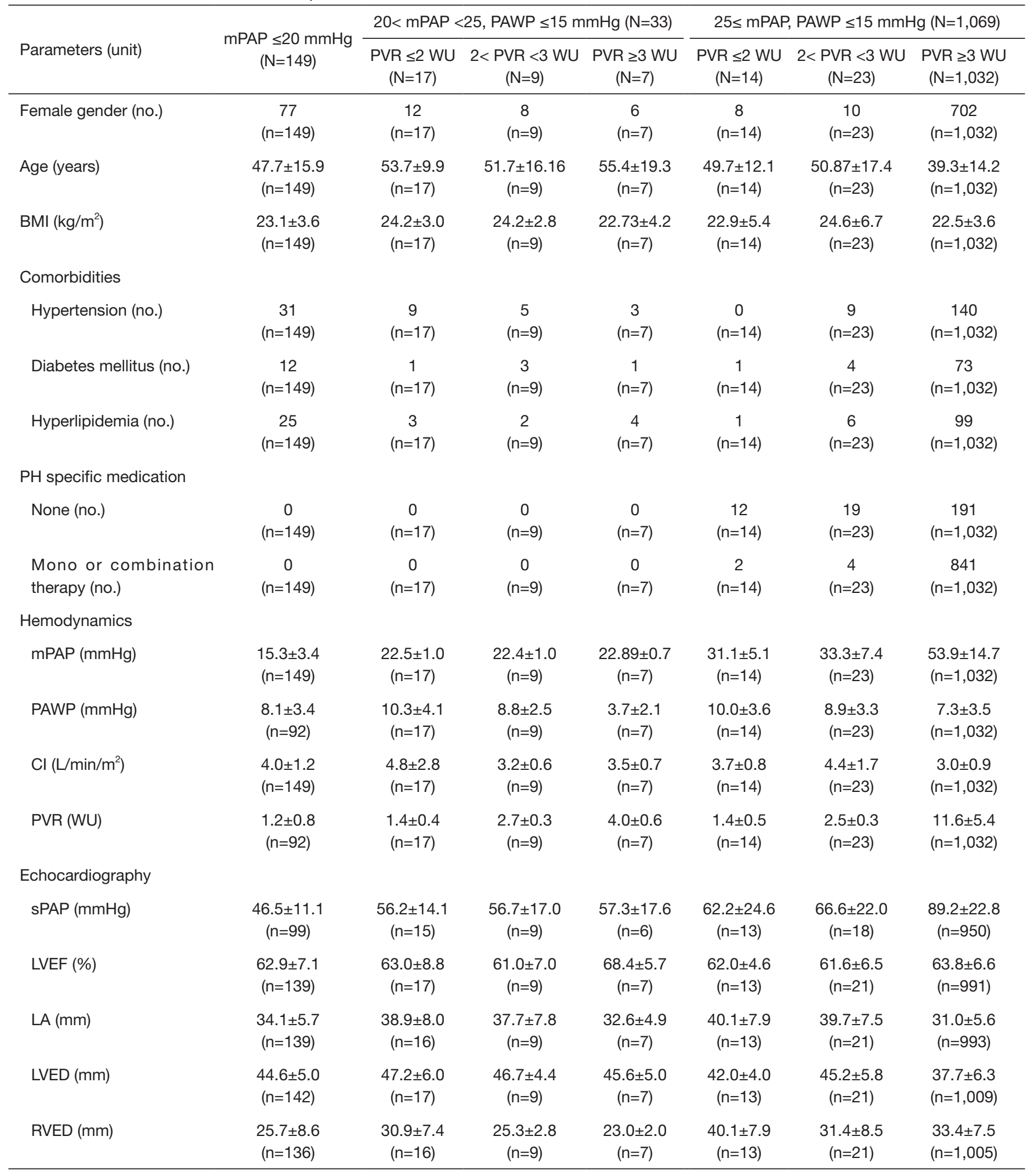

Table 1 (continued) 
Table 1 (continued)

\begin{tabular}{|c|c|c|c|c|c|c|c|}
\hline \multirow[b]{2}{*}{ Parameters (unit) } & \multirow{2}{*}{$\begin{array}{c}\mathrm{mPAP} \leq 20 \mathrm{mmHg} \\
(\mathrm{N}=149)\end{array}$} & \multicolumn{3}{|c|}{$20<\mathrm{mPAP}<25$, PAWP $\leq 15 \mathrm{mmHg}(\mathrm{N}=33)$} & \multicolumn{3}{|c|}{$25 \leq \mathrm{mPAP}, \mathrm{PAWP} \leq 15 \mathrm{mmHg}(\mathrm{N}=1,069)$} \\
\hline & & $\begin{array}{c}P V R \leq 2 \text { WU } \\
(\mathrm{N}=17)\end{array}$ & $\begin{array}{c}2<\mathrm{PVR}<3 \mathrm{WU} \\
(\mathrm{N}=9)\end{array}$ & $\begin{array}{c}P V R \geq 3 \text { WU } \\
(N=7)\end{array}$ & $\begin{array}{c}P V R \leq 2 \text { WU } \\
(N=14)\end{array}$ & $\begin{array}{c}2<\mathrm{PVR}<3 \mathrm{WU} \\
(\mathrm{N}=23)\end{array}$ & $\begin{array}{c}P V R \geq 3 \mathrm{WU} \\
(\mathrm{N}=1,032)\end{array}$ \\
\hline $\mathrm{P}_{\mathrm{ET}} \mathrm{CO}_{2} @$ Peak $(\mathrm{mmHg})$ & $\begin{array}{c}37.4 \pm 6.4 \\
(n=124)\end{array}$ & $\begin{array}{c}37.0 \pm 3.0 \\
(n=14)\end{array}$ & $\begin{array}{c}30.4 \pm 4.6 \\
(n=8)\end{array}$ & $\begin{array}{c}33.7 \pm 7.7 \\
(n=6)\end{array}$ & $\begin{array}{c}34.8 \pm 4.9 \\
(n=13)\end{array}$ & $\begin{array}{c}36.6 \pm 9.1 \\
(n=18)\end{array}$ & $\begin{array}{c}24.3 \pm 6.5 \\
(n=866)\end{array}$ \\
\hline VO $\mathrm{V}_{2} / \mathrm{HR} @$ Peak (mL/beat) & $\begin{array}{l}8.5 \pm 2.5 \\
(n=124)\end{array}$ & $\begin{array}{c}8.8 \pm 2.7 \\
(n=14)\end{array}$ & $\begin{array}{c}6.3 \pm 1.6 \\
(n=8)\end{array}$ & $\begin{array}{c}6.7 \pm 2.0 \\
(n=6)\end{array}$ & $\begin{array}{c}7.3 \pm 2.9 \\
(n=13)\end{array}$ & $\begin{array}{c}8.6 \pm 2.9 \\
(n=18)\end{array}$ & $\begin{array}{l}5.8 \pm 3.4 \\
(n=866)\end{array}$ \\
\hline $\mathrm{VO}_{2} @$ Peak $(\mathrm{mL} / \mathrm{min} / \mathrm{kg})$ & $\begin{array}{c}19.2 \pm 5.4 \\
(n=124)\end{array}$ & $\begin{array}{c}17.2 \pm 4.2 \\
(n=14)\end{array}$ & $\begin{array}{c}14.7 \pm 3.7 \\
(n=8)\end{array}$ & $\begin{array}{c}13.7 \pm 4.0 \\
(n=6)\end{array}$ & $\begin{array}{c}14.2 \pm 5.3 \\
(n=13)\end{array}$ & $\begin{array}{c}16.3 \pm 3.8 \\
(n=18)\end{array}$ & $\begin{array}{c}12.8 \pm 3.6 \\
(n=865)\end{array}$ \\
\hline
\end{tabular}

Data are presented as mean \pm standard deviation (sample size) or number (sample size). BMI, body mass index; Cl, cardiac index; CPET, cardiopulmonary exercise testing; HR, heart rate; LA, left atrium dimension; LVED, left ventricular end-diastolic diameter; LVEF, left ventricular ejection fraction; mPAP, mean pulmonary arterial pressure; PAWP, pulmonary arterial wedge pressure; $\mathrm{P}_{\mathrm{ET}} \mathrm{CO}_{2}$, endtidal partial pressure of carbon dioxide; $\mathrm{PH}$, pulmonary hypertension; PVR, pulmonary vascular resistance; RVED, right ventricular enddiastolic diameter; sPAP, systolic pulmonary arterial pressure; $\mathrm{VCO}_{2}$, carbon dioxide output; $\mathrm{VE}$, minute ventilation; $\mathrm{VO}_{2}$, oxygen uptake; WU, wood units.

(Group I, N=2; Group III, N=1; Group IV, N=4), and the remaining 26 patients with PVR $<3 \mathrm{WU}$ were subgrouped as having unclassifiable $\mathrm{PH}$. A flow diagram displaying the impact of the newly revised hemodynamic definition on current clinical practice is shown in Figure 3. Detailed characteristics of the newly identified precapillary $\mathrm{PH}$ patients are shown in Table 2.

\section{Distribution of the underlying etiology of $\mathrm{PH}$}

We stratified patients with $\mathrm{mPAP}>20 \mathrm{mmHg}$ and PAWP $\leq 15 \mathrm{mmHg}$ according to $\mathrm{mPAP}$ and PVR $(\mathrm{N}=1,101)$ (Figure 4). Sixty-three of these patients had PVR $<3 \mathrm{WU}$, among which the most common underlying etiology was congenital heart disease $(\mathrm{N}=34)$, followed by unclear/ multifactorial mechanisms (N=16), CTE $(\mathrm{N}=5)$, lung diseases $(\mathrm{N}=5)$, other pulmonary artery obstructions $(\mathrm{N}=2)$ and connective tissue diseases $(\mathrm{N}=1)$.

\section{Patients with chronic thromboembolism}

For the former CTEPD patients diagnosed by the 2015 ESC/ERS guidelines, 4 (40\%) of 10 were reclassified as CTEPH for mPAP $>20 \mathrm{mmHg}$, PAWP $\leq 15 \mathrm{mmHg}$ and $\mathrm{PVR} \geq 3 \mathrm{WU}$ (Figure 3). Among the remaining 6 patients, one patient had mPAP $>20 \mathrm{mmHg}$, PAWP $\leq 15 \mathrm{mmHg}$ and PVR $<3 \mathrm{WU}$, so this patient was classified as unclassifiable
PH (Figure 4). Surprisingly, 4 (1.8\%) of the former patients with CTEPH $(\mathrm{N}=218)$ as diagnosed by the $2015 \mathrm{ESC} /$ ERS guidelines, were also re-classified as unclassifiable $\mathrm{PH}$ for PVR $<3 \mathrm{WU}$ (Figure 3). The detailed characteristics of these 5 patients with CTE and abnormal hemodynamics are exhibited in Table 3.

\section{Discussion}

In a tertiary $\mathrm{PH}$ center in China, we found that the $6^{\text {th }}$ WSPH criteria had a minor impact on the diagnosis of precapillary $\mathrm{PH}$. Seven patients with borderline $\mathrm{PH}$ (mPAP $=21-24 \mathrm{mmHg}$ ) were newly identified as having precapillary $\mathrm{PH}$, while 12 patients with overt $\mathrm{PH}$ (mPAP $>25 \mathrm{mmHg}$ ) were delisted from precapillary $\mathrm{PH}$ due to PVR $<3$ WU. Taken together, there wasan overall $0.5 \%$ net decrease $[(12-7) / 1044 \times 100 \%]$ in the population with precapillary $\mathrm{PH}$.

\section{Newly identified patients with pre-capillary $\mathrm{PH}$}

After using the $6^{\text {th }}$ WSPH criteria to reclassifying patients diagnosed by the 2015 ESC/ERS guidelines, 33 (18.1\%) of 182 patients with $\mathrm{mPAP}<25 \mathrm{mmHg}$ were newly identified as having $\mathrm{PH}$. However, only 7 (21.2\%) of these 33 patients had a PVR $\geq 3$ WU and could be considered to have precapillary $\mathrm{PH}$, which only accounted for $0.7 \%$ of the 


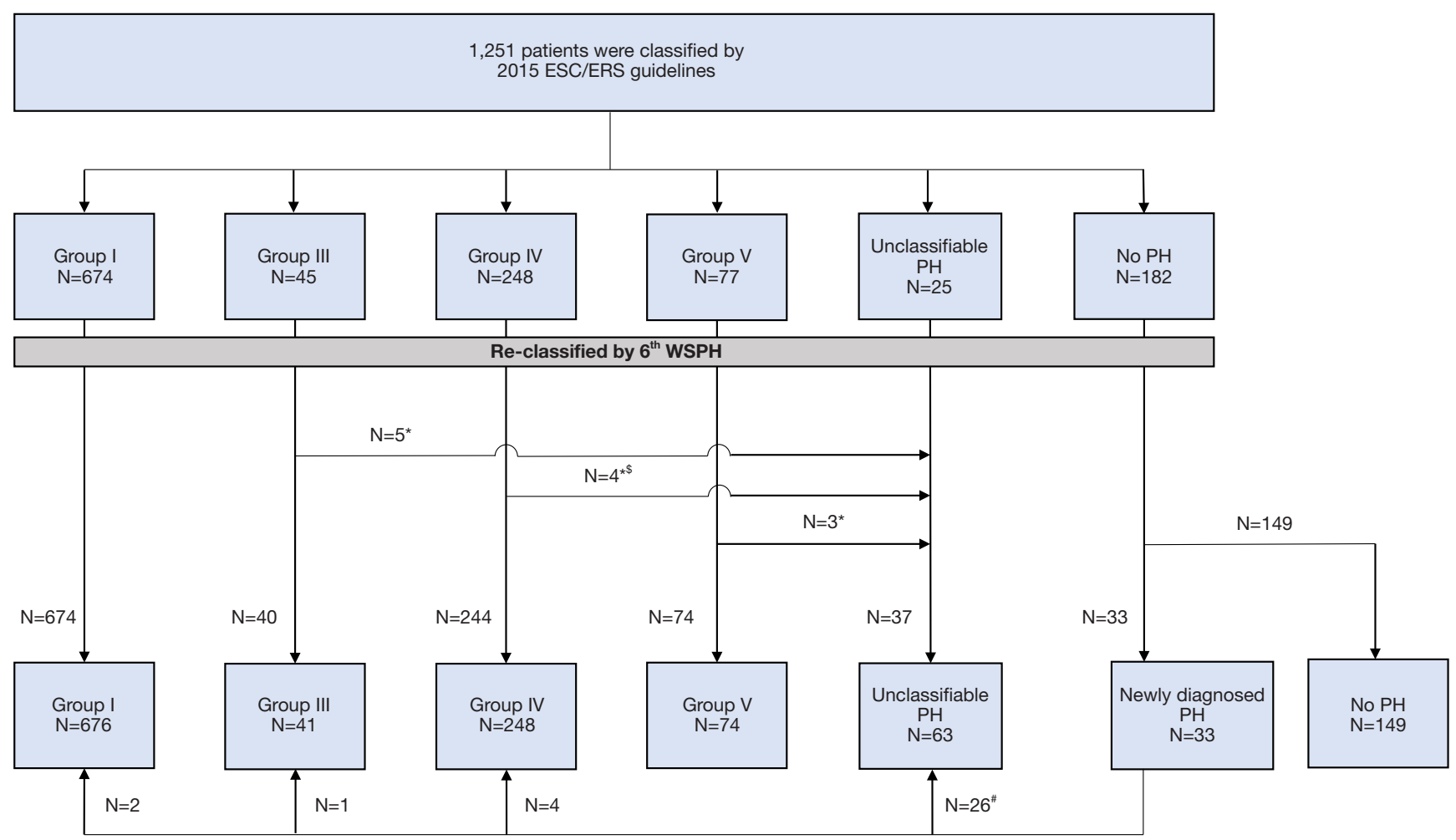

Figure 3 The $6^{\text {th }}$ WSPH was used to reclassify PH patients diagnosed by the 2015 ESC/ERS guidelines. *, Those patients could no longer be considered as having precapillary $\mathrm{PH}$ due to $\mathrm{PVR}<3$ wood units under the $6^{\text {th }} \mathrm{WSPH}$ criteria. * , The underlying etiology of the PH of the patients (mPAP 21-24 mmHg, PVR <3 wood units) is shown in Figure 4. ${ }^{\text {, }}$, All patients had chronic thromboembolic pulmonary hypertension. ERS, European Respiratory Society; ESC, European Society of Cardiology; mPAP, mean pulmonary arterial pressure; PH, pulmonary hypertension; PVR, pulmonary vascular resistance; WSPH, World Symposium on Pulmonary Hypertension.

Table 2 Detailed characteristics of newly identified and classifiable patients according to the $6^{\text {th }}$ WSPH criteria

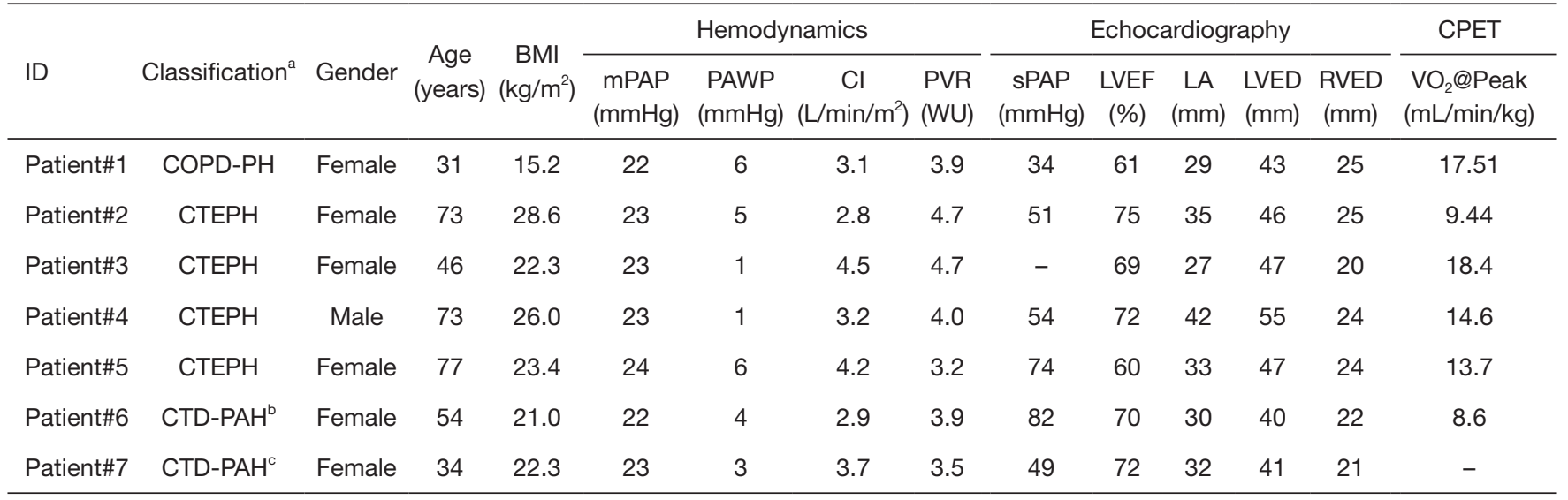

${ }^{\mathrm{a}}$, Based on the $6^{\text {th }}$ WSPH criteria. ${ }^{\mathrm{b}}$, PAH associated with mixed connective tissue diseases. ${ }^{\mathrm{C}}$, PAH associated with systemic lupus erythematosus. BMI, body mass index; $\mathrm{Cl}$, cardiac index; COPD, chronic obstructive pulmonary disease; CTEPH, chronic thromboembolic pulmonary hypertension; LA, left atrium dimension; LVED, left ventricular end-diastolic diameter; LVEF, left ventricular ejection fraction; mPAP, mean pulmonary arterial pressure; $\mathrm{PAH}$, pulmonary arterial hypertension; PAWP, pulmonary arterial wedge pressure; $\mathrm{PH}$, pulmonary hypertension; PVR, pulmonary vascular resistance; RVED, right ventricular end-diastolic diameter; sPAP, systolic pulmonary arterial pressure; $\mathrm{VO}_{2}$, oxygen uptake; WSPH, World Symposium on Pulmonary Hypertension. 


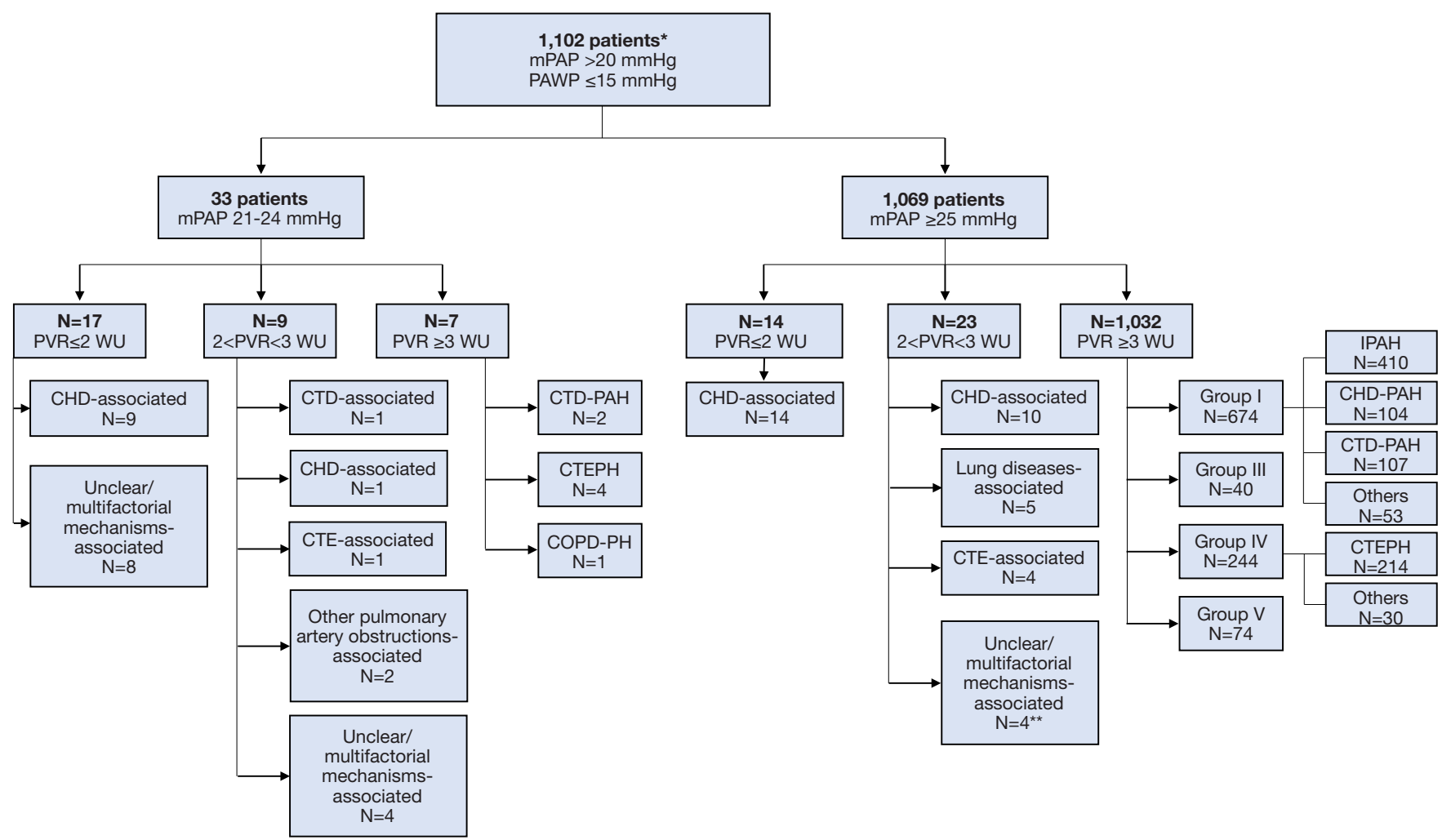

Figure 4 The underlying etiology of precapillary PH in 1,102 patients, stratified by mPAP and PVR. *, Classification is based on the $6^{\text {th }}$ WSPH. **, One patient was diagnosed as IPAH by the 2009 ESC/ERS guidelines at first and then reclassified as having unclassifiable $\mathrm{PH}$ by the $2015 \mathrm{ESC} / \mathrm{ERS}$ guidelines due to PVR $\leq 3$. Therefore, the underlying etiology of $\mathrm{PH}$ in this patient is considered unclear/ multifactorial. The remaining 3 patients were from Group V as directly diagnosed by the 2015 ESC/ERS guidelines (see Figures 2,3). CHD, congenital heart disease; CTD, connective tissue diseases; CTE, chronic thromboembolism; CTEPH, chronic thromboembolic pulmonary hypertension; COPD, chronic obstructive pulmonary disease; ERS, European Respiratory Society; ESC, European Society of Cardiology; IPAH, idiopathic pulmonary arterial hypertension; mPAP, mean pulmonary arterial pressure; PAWP, pulmonary arterial wedge pressure; $\mathrm{PH}$, pulmonary hypertension; PVR, pulmonary vascular resistance.

Table 3 Detailed characteristics of unclassifiable patients with CTE-PH

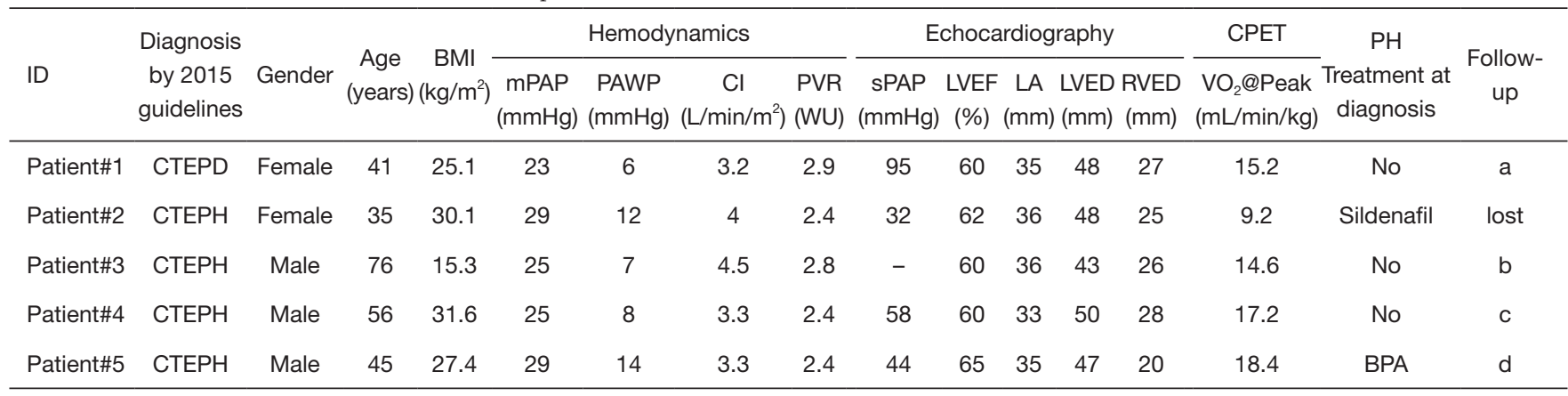

${ }^{a}$, Progressing to CTEPH (2 years after diagnosis); ${ }^{b}$, Deteriorated echocardiography (2 years after diagnosis); ${ }^{\circ}$, mPAP increased by $2 \mathrm{mmHg}$ (1 years after diagnosis); ${ }^{\mathrm{d}}$, No change in mPAP (2 years after diagnosis). BPA, balloon pulmonary angioplasty; BMI, body mass index; Cl, cardiac index; CTE, chronic thromboembolism; CTEPD, chronic thromboembolic pulmonary disease; LA, left atrium dimension; LVED, left ventricular end-diastolic diameter; LVEF, left ventricular ejection fraction; mPAP, mean pulmonary arterial pressure; PAWP, pulmonary arterial wedge pressure; $\mathrm{PH}$, pulmonary hypertension; PVR, pulmonary vascular resistance; RVED, right ventricular enddiastolic diameter; sPAP, systolic pulmonary arterial pressure; $\mathrm{VO}_{2}$, oxygen uptake. 
existing precapillary $\mathrm{PH}$ population. Consistent with our results, Tanyeri et al. (7) reported that the revised definition would only increase the population of precapillary $\mathrm{PH}$ by $0.8 \%$.

Some studies reported that the revised definitions would result in an increase of $4.5 \%$ to $12.1 \%$ in the existing precapillary $\mathrm{PH}$ population, mainly SSc-PAH $(4,5)$. This divergence should be attributed to the differences in the characteristics of the study cohorts. In the aforementioned studies $(4,5)$, the patients were all enrolled from prospective cohorts undergoing $\mathrm{PH}$-screening algorithms. The number of patients with $\mathrm{mPAP} \geq 25 \mathrm{mmHg}$ (e.g., $\mathrm{N}=33$ ) was small and they were similar to patients with $20<\mathrm{mPAP}$ $<25 \mathrm{mmHg}$ (e.g., $\mathrm{N}=55$ ) and $\mathrm{mPAP} \leq 20 \mathrm{mmHg}$ (e.g., $\mathrm{N}=146)$. Therefore, even a small number of patients being reclassified as having pre-capillary $\mathrm{PH}$ (e.g., $\mathrm{N}=4$ ) would cause a relatively large increase in the existing precapillary PH population (e.g., 4/33=12.1\%). In contrast, the number of patients with precapillary PH $(\mathrm{N}=1,044)$ in the present study was far greater than those with $20<\mathrm{mPAP}<25 \mathrm{mmHg}(\mathrm{N}=33)$. This might explain why the revised definitions only had a minor impact on the general $\mathrm{PH}$ population in our study, while it had relatively larger impact on the $\mathrm{PH}$-screening cohort (e.g., systemic sclerosis). When we looked at the proportion of newly identified precapillary $\mathrm{PH}$ in patients with $20<\mathrm{mPAP}$ $<25 \mathrm{mmHg}$, our results (21.2\%) were much closer to previous studies $(5.3 \%$ to $11.1 \%)(4,5)$, which further supported our explanation of the divergence. It should be noted that a study from a tertiary cardiology center reported that the revised definitions could increase the existing precapillary $\mathrm{PH}$ population by $12.1 \%$. Nevertheless, their study cohort was too small $(\mathrm{N}=58)$, which limited the generalizability of their conclusion (6).

\section{Newly identified patients with unclassifiable PH}

After application of the revised definitions, 38 patients were reclassified as having unclassifiable $\mathrm{PH}$ due to PVR $<3$, leading to a $152 \%$ increase (from 25 to 63 ) in the unclassifiable $\mathrm{PH}$ population (Figure 3). Among these 38 patients, 26 patients came from the former No $\mathrm{PH}$ group (i.e., $\mathrm{mPAP}=21-24 \mathrm{mmHg}, \mathrm{PAWP} \leq 15 \mathrm{mmHg}$ and PVR $<3 \mathrm{WU}$ ), of whom the underlying etiology is detailed in Figure 4. Surprisingly, the remaining 12 patients came from the former precapillary $\mathrm{PH}$ group (i.e., $\mathrm{mPAP} \geq 25 \mathrm{mmHg}$, PAWP $\leq 15 \mathrm{mmHg}$ and PVR $<3 \mathrm{WU}$ ). Seven patients with borderline $\mathrm{PH}$ were newly identified as having precapillary
$\mathrm{PH}$, while 12 patients with overt $\mathrm{PH}$ were delisted from pre-capillary $\mathrm{PH}$ group because of PVR $<3 \mathrm{WU}$. Therefore, there was an overall $0.5 \%$ net decrease [(12-7)/1044×100\%] in the population with precapillary $\mathrm{PH}$, which is contrary to the expectation that the revised definition may result in a small increase in the population of pre-capillary PH.

\section{Patients with CTE-PH}

Currently, it remains unclear how the revised definitions will affect the management of CTEPH and CTEPD (13). In the present study, we found that 4 (40\%) of 10 former patients with CTEPD were reclassified as having CTEPH. More importantly, the revised definition created a new subgroup in Group IV (1 patient from the former CTEPD group and 4 patients from the former CTEPH group), which we named CTE-PH. Patients with CTE-PH had mPAP $>20 \mathrm{mmHg}, \mathrm{PAWP} \leq 15 \mathrm{mmHg}$ and $\mathrm{PVR}<3 \mathrm{WU}$. Therefore, CTE-PH could be classified as neither CTEPH (for PVR $<3 \mathrm{WU}$ ) nor CTEPD (for mPAP $>20 \mathrm{mmHg}$ ) under the $6^{\text {th }}$ WSPH criteria. Where should CTE-PH be placed within Group IV? How do we manage these patients? Unfortunately, such questions were not answered in the $6^{\text {th }}$ WSPH. Furthermore, those unanswered questions may disrupt clinical decision-making and cause a delay in treatment. Table 3 summarizes the detailed characteristics (including the treatment strategy and the follow-up information) of these five patients with CTE-PH in our center. Similar problems were also observed within Groups III and V (Figure 3). Given that there is no specific therapy for Groups III and V, the detailed characteristics of unclassifiable PH patients from Groups III and V were not listed.

\section{Limitations}

Our single-center retrospective study has several limitations. First, the retrospective design introduces inherent selection bias. Hemodynamic studies have been performed only in patients with suspected pulmonary hypertension according to the former definition. Therefore, our results might not reflect the "real" impact of the new definition. A prospective study with a large sample size is needed to address this issue. Second, 209 (13.7\%) of 1,523 patients were excluded from the present study for incomplete hemodynamic data. Among these 209 patients, only 4 patients had missing mPAP and 4 patients had $20<$ mPAP $<25 \mathrm{mmHg}$. Even though all 8 patients fulfilled the revised definitions, it would only 
change our results from $0.7 \%$ to $1.4 \%$. Thus, the exclusion of these 209 patients would not undermine our conclusion. Third, as a tertiary $\mathrm{PH}$ center in a cardiology specialist hospital, the spectrum of the underlying etiology of $\mathrm{PH}$ in our center may differ from that of others, which may limit the generalizability of our conclusion. For instance, patients from Group II are usually treated in the Heart Failure Care Unit in our hospital and patients from Group III are rarely seen in our hospital. Last, we failed to offer clinical outcome of patients with newly diagnosed PH. The longterm prognosis and therapeutic strategies for these patients require further research in the future.

\section{Conclusions}

The revised hemodynamic definition had a minor impact on current clinical practice. Only 7 patients with borderline $\mathrm{PH}$ were reclassified as the precapillary $\mathrm{PH}$ population, which accounted for $0.7 \%$ of the former precapillary $\mathrm{PH}$ population. However, 12 patients with overt $\mathrm{PH}$ could no longer be considered as having precapillary $\mathrm{PH}$ due to PVR $<3$ WU. Thus, there was a $0.5 \%$ net decrease in the population with precapillary $\mathrm{PH}$. Management strategies for patients delisted from precapillary $\mathrm{PH}$ require further discussion.

\section{Acknowledgments}

We thank American Journal Experts (https://www.aje.com) for their assistance with the language editing.

Funding: This research article was supported by Beijing Municipal Science and Technology Project [grant number Z181100001718200]; Beijing Municipal Natural Science Foundation [grant number 7202168] and National Precision Medical Research Program of China [grant number 2016YFC0905602]; CAMS Innovation Fund for Medical Sciences (CIFMS) [2020-I2M-C\&T-B-055]; the Capital's Funds for Health Improvement and Research (CFH) [20202-4033].

\section{Footnote}

Reporting Checklist: The authors have completed the STROBE reporting checklist. Available at https://dx.doi. org/10.21037/cdt-21-373

Data Sharing Statement: Available at https://dx.doi. org/10.21037/cdt-21-373
Conflicts of Interest: All authors have completed the ICMJE uniform disclosure form (available at https://dx.doi. org/10.21037/cdt-21-373). The authors have no conflicts of interest to declare.

Ethical Statement: The authors are accountable for all aspects of the work in ensuring that questions related to the accuracy or integrity of any part of the work are appropriately investigated and resolved. The study was conducted in accordance with the Declaration of Helsinki (as revised in 2013). The study was approved by ethics board of Fuwai Hospital (NO.: 2019-1191) and individual consent for this retrospective analysis was waived.

Open Access Statement: This is an Open Access article distributed in accordance with the Creative Commons Attribution-NonCommercial-NoDerivs 4.0 International License (CC BY-NC-ND 4.0), which permits the noncommercial replication and distribution of the article with the strict proviso that no changes or edits are made and the original work is properly cited (including links to both the formal publication through the relevant DOI and the license). See: https://creativecommons.org/licenses/by-nc-nd/4.0/.

\section{References}

1. Galiè N, Humbert M, Vachiery JL, et al. 2015 ESC/ERS Guidelines for the diagnosis and treatment of pulmonary hypertension: The Joint Task Force for the Diagnosis and Treatment of Pulmonary Hypertension of the European Society of Cardiology (ESC) and the European Respiratory Society (ERS): Endorsed by: Association for European Paediatric and Congenital Cardiology (AEPC), International Society for Heart and Lung Transplantation (ISHLT). Eur Respir J 2015;46:903-75.

2. Galiè N, Hoeper MM, Humbert M, et al. Guidelines for the diagnosis and treatment of pulmonary hypertension: the Task Force for the Diagnosis and Treatment of Pulmonary Hypertension of the European Society of Cardiology (ESC) and the European Respiratory Society (ERS), endorsed by the International Society of Heart and Lung Transplantation (ISHLT). Eur Heart J 2009;30:2493-537.

3. Simonneau G, Montani D, Celermajer DS, et al. Haemodynamic definitions and updated clinical classification of pulmonary hypertension. Eur Respir J 2019;53:1801913.

4. Xanthouli P, Jordan S, Milde N, et al. Haemodynamic 
phenotypes and survival in patients with systemic sclerosis: the impact of the new definition of pulmonary arterial hypertension. Ann Rheum Dis 2020;79:370-8.

5. Jaafar S, Visovatti S, Young A, et al. Impact of the revised haemodynamic definition on the diagnosis of pulmonary hypertension in patients with systemic sclerosis. Eur Respir J 2019;54:1900586.

6. Sinan ÜY, Çetinarslan Ö, Arat Özkan A, et al. The impact of the new World Symposium on Pulmonary Hypertension definition of pulmonary hypertension on the prevalence of pre-capillary pulmonary hypertension. Turk Kardiyol Dern Ars 2019;47:594-8.

7. Tanyeri S, Akbal OY, Keskin B, et al. Impact of the updated hemodynamic definitions on diagnosis rates of pulmonary hypertension. Pulm Circ 2020;10:2045894020931299.

8. Delcroix M, Torbicki A, Gopalan D, et al. ERS Statement on Chronic Thromboembolic Pulmonary Hypertension. Eur Respir J 2021;57:2002828.

Cite this article as: Jin Q, Zhang $\mathrm{Y}$, Zhao Z, Zhao Q, Yu X, Yan L, Li X, Duan A, An C, Ma X, Xiong C, Luo Q, Liu Z. Impact of the revised hemodynamic definition on the diagnosis of precapillary pulmonary hypertension: a retrospective singlecenter study in China. Cardiovasc Diagn Ther 2021;11(5):10471057. doi: $10.21037 /$ cdt-21-373
9. Tang Y, Luo Q, Liu Z, et al. Oxygen Uptake Efficiency Slope Predicts Poor Outcome in Patients With Idiopathic Pulmonary Arterial Hypertension. J Am Heart Assoc 2017;6:e005037.

10. Zhang HL, Liu ZH, Wang Y, et al. Acute responses to inhalation of Iloprost in patients with pulmonary hypertension. Chin Med J 2012;125:2826-31.

11. Yu X, Luo Q, Liu Z, et al. Prevalence of iron deficiency in different subtypes of pulmonary hypertension. Heart Lung 2018;47:308-13.

12. Jin Q, Luo Q, Yang T, et al. Improved hemodynamics and cardiopulmonary function in patients with inoperable chronic thromboembolic pulmonary hypertension after balloon pulmonary angioplasty. Respir Res 2019;20:250.

13. Kim NH, Delcroix M, Jais X, et al. Chronic thromboembolic pulmonary hypertension. Eur Respir J 2019;53:1801915. 